\title{
Discurso del Coordinador Principal del Centro de Investigación Científica en el marco de la presentación pública del séptimo número de la revista "Policía y Seguridad Pública"
}

Señor Viceministro de la Defensa Nacional: General de Aviación Jaime Leonardo Parada González.

Señor Director General de la Academia Nacional de Seguridad Pública: Lic. Jaime Edwin Martínez Ventura.

Señores titulares y funcionarios de las diferentes dependencias del Ministerio de Justicia y Seguridad Pública.

Señor Sub Director Ejecutivo de la Academia Nacional de Seguridad Pública: Comisionado José Manuel Olivares Rivera.

Señores subdirectores, jefes y personal operativo de la Policía Nacional Civil.

Señores jefes policiales de esta academia e invitados especiales tengan todos muy buenos días.

El Salvador se inscribe en uno de los entornos más complejos de seguridad que se hayan generado en la posguerra, ante tal adversidad resulta imposible permanecer impávido mientras las organizaciones criminales pandilleriles secuestran progresivamente el tejido social en el territorio y la comunidad; desafían peligrosamente a la autoridad pública e intentan doblegar el esfuerzo y las iniciativas de todos aquellos que se les oponen. El problema fundamental acá es que también ha mediado la falta de voluntad en el Estado para imponerse y la complicación de los buenos ciudadanos para entenderse y conducirse como uno solo. Todos se trasladan culpas y responsabilidades, se demandan políticas inteligentes, esfuerzos acertados, ello ocurre mientras algunos se quejan de no contar con los recursos suficientes y otros de derrocharlos en acciones inútiles y poco pensadas que no contribuyen a dar un vuelco significativo a la situación. Otros traen unas exigencias pesadas y con poca factibilidad sin reparar que en sus roles de juzgadores y aplicadores de la ley tuercen la justicia en sus subterfugios legales y tecnicismos minúsculos que fortalecen el estado de cosas; desechan a los justos y reivindican a los malos, realidad tan palpable que ratifica aquel pasaje escritural en el evangelio de Lucas que reza de la siguiente manera; abro comillas: “... hay de vosotros también intérpretes de la ley porque cargáis a los hombres con cargas que no pueden llevar pero vosotros ni aun con un dedo las tocáis..." cierro comillas. 
Veamos la radiografía de un caso bélico y perdonen que use esa categoría. A mediados de 2008 un joven profesional y su novia fueron objetos de un robo agravado, en instantes fueron despojados del vehículo en que se encontraban, hubo intento de secuestro y huir del lugar con paradero desconocido, escena de pánico que incluyó que una de las víctimas recibiera golpes constantes en la cabeza con las empuñadoras de dos pistolas. Los atacantes miembros de la mara salvatrucha fueron apresados una semana después y no obstante los cargos que se les acumularon como privación de libertad, robo agravado, amenazas agravadas, lesiones y otros, fueron beneficiados por una figura llamada suspensión condicional del procedimiento; algo que les favoreció y les convirtió sus delitos graves por arte de magia en un tecnicismo de receptación, lo curioso fue que según consta en el expediente penitenciario venían de quedar libres por los mismo dos meses atrás. El caso se fue extinguiendo mientras los descuidados operarios del sistema judicial remitían correspondencia errónea con datos de la víctima al domicilio del victimario y viceversa; para indicar dónde podía pagar su fianza. Semejantes expresiones de justicia torcida no provocan más que repudio y clamor por la reforma radical del sector justicia y de las leyes.

No eternicemos posturas de autocomplacencia llamando a la impunidad parienta, como sería la existencia de un entorno complejo de seguridad; en que el Estado mismo se comporta como el peor enemigo de sí mismo y hablo de Estado en su conjunto porque no sólo se trata de un órgano. La pregunta anterior no la hago en el aire sino que la asumo como la expresión de la incapacidad del Estado para prevalecer sobre el estado de cosas imperantes; veamos algunos signos de estos tiempos; nadie es profeta en su tierra, arribamos a un nuevo esfuerzo de publicación con la certeza de que será vitoreado por unos instantes pero luego se guardará junto a una inmensa pira de libros, documentos y otros estudios que no tendrán valor de uso alguno; esta es la tragedia que se cierne sobre los actores de la seguridad; que al no leer estos productos deciden cómodamente vetar y desconocer los mejores esfuerzos de quién genuinamente desean cambiar la situación de inseguridad y criminalidad que impera en el país, estos tienen defectos: Primero son salvadoreños, segundo son descalificados por militar en las mismas filas del Estado y tercero porque resulta imposible que en este país puedan existir mentes tan lúcidas y brillantes.

Todo lo anterior corrobora que el estímulo probable para lo que puede llamarse buen lector es la implementación del castigo de la no lectura. Si decidimos no leer estos trabajos optamos por un harakiri moral y por lo tanto por no conocer y por ende por no rectificar y en definitiva por apoltronarnos en nefastos endiosamientos; por ello se ha hecho costumbre evocar resúmenes de las investigaciones, hojas ejecutivas porque no hay tiempo disponible en esas ciento sesenta y ocho horas que se distribuyen en la semana. Así que profetas váyanse a otras tierras, tal vez en ellas 
valoren estos esfuerzos, no me refiero a gentes con auras especiales sino a aquellos que genuinamente entienden los tiempos y trabajan contra la adversidad de las épocas.

\section{¿El Salvador en guerra?}

El Salvador está en un nuevo tipo de guerra, actores criminales en este caso las pandillas han impuesto el terror a buena parte de la población, han arrebatado el control territorial en la comunidad; y el Estado en toda la posguerra apenas y lo ha impedido. Una guerra se caracteriza por los bandos enfrentados, por el nivel de victimización, por los procesos de violencia general, por el desplazamiento de población, por la lucha de la influencia social, por los desconocimientos y descalificaciones mutuas entre los actores principales; pero sobre todo incluso por las declaraciones desde el Estado dónde se podría asumir que tal estado de naturaleza es exagerado o simplemente no existe y que es espejismo, todo esto ocurre mientras estos grupos de pandillas transnacionales intentan imponer un orden criminal buscando prevalecer por el miedo.

El Estado está llamado a impedir que la maldad de unos pocos impongan una vida corta y brutal para los buenos ciudadanos para decirlo al mejor estilo hobbsiano.

\section{¿Perlas para los cerdos?}

En El Salvador pocos saben que es una indización especializada, pocos conocen los logros de la revista "Policía y Seguridad Pública" como journal de seguridad, otros la consideran un proyecto sumamente astral, complejo, sofisticado que también es una suerte de malas palabras pronunciadas de forma rebuscada; pero en definitiva también descalificadora. Una cosa es segura no la conocen, nunca la han leído, nunca han preguntado cómo se confecciona cada número ¿No es esto una negligencia tan grande? ¿Cómo es posible que no conozcamos lo nuestro? ¿Por qué no reivindicamos el talento de aquellos que intentan estar comprometidos con el bienestar de la gente? La omisión es grave y el hacer es mucho pero de forma mal concebida también lo es, porque se transforma en el reinado de los cardos y los espinos. No convirtamos este esfuerzo y estas publicaciones en pasquines ideologizados y estilizados, la investigación en seguridad en cara, no es para tertulias académicas, ni para efectos mediáticos; quien así la concibe no tiene interés real para enfrentar los problemas, puesto que se trata de una iniciativa de fondo. Por ello el Centro de Investigación Científica moviliza en su planificación una agenda que se aproxime a temáticas sensibles para el impacto y la transformación del sector, comprometámonos pues a derribar el reinado de los cardos y los espinos; seamos embajadores del proyecto y ayudemos a hacerla circular en las comunidades de seguridad. 
Finalizo con estas palabras a lo mejor que no sean tan gratas; pero es necesario expresarlas so pena que la parafernalia de lo políticamente correcto termine trayendo indeseables reflujos, y me refiero a lo siguiente: El Salvador necesita investigación avanzada para la seguridad, programas serios y bien financiados de estudios estratégicos para impacto en áreas críticas del sector; así que llamo a desistir de proyectos que pregonan conocer la realidad pero no se enfrentan con ella, por eso el logo del CINC es el farol antiguo que representa el imperativo de verdad, pensémoslo dos veces y hagámoslo bien para que no seamos contados. Y cito nuevamente las Escrituras, y abro comillas: “... hay de vosotros intérpretes de la ley, porque habéis quitado la llave de la ciencia, vosotros mismos no entrasteis y a los que entraban se lo impedisteis...", que deshonra más grande ser incluido en este grupo, así que los exhorto a que nos renovemos en el entendimiento y en el compromiso auténtico por el país.

Quiero finalmente expresar mis agradecimientos a dos autores internacionales que han participado en este proyecto, en este número Margriet Zoethout de nacionalidad holandesa y a Santiago Herrero Blanco de Catalunya, España; ellos han participado con dos importantes investigaciones, yo les voy a pedir que por este medio tecnológico que tenemos en este momento los sepamos aprovechar, porque por ejemplo en el caso de Catalunya se ha logrado mapear en este trabajo que hoy se presenta, la presencia de esta comunidad criminal en la Península Ibérica y nos puede dar una idea de cómo se puede cooperar en ambos lados del Atlántico y en el caso del otro trabajo es una radiografía de las dinámicas del control social y territorial en una comunidad dominada por pandillas. Es un trabajo que debería ser de lectura obligatoria para todo el mando estratégico e intermedio de la Policía Nacional Civil. Yo me quedo hasta acá, muchas gracias por su atención.

Juan Carlos Morales Peña

Miércoles 23 de septiembre de 2015 